\title{
Evaluation of Factors Affecting Delamination, Tensile Strength, Thrust Force and Surface Roughness in Drilling of GFRP
}

Erol KILICKAP

Dicle University

Yahya Hışman Celik

Batman University

Burak Yenigun ( $\sim$ byenigun@yorku.ca )

York University https://orcid.org/0000-0002-7260-3797

Original Research

Keywords: GFRP, Tensile Strength, Delamination, Thrust Force, Surface Roughness, Temperature, Drilling

Posted Date: February 12th, 2021

DOl: https://doi.org/10.21203/rs.3.rs-207947/v1

License: (c) (i) This work is licensed under a Creative Commons Attribution 4.0 International License.

Read Full License 


\section{Abstract}

The drilling operation of glass fiber reinforced plastic (GFRP) composites has gained importance because they are used as structural components in many industries such as aerospace and aviation. In the drilling of GFRP composites, some problems such as deformation and fiber breakage occur. Thrust force, delamination, surface quality and cutting temperature are affected by drilling parameters and woven types in the drilling of GFRP composites. At the same time, delamination also affects tensile strength. In this study, the effects of drilling parameters and woven types of GFRP composites on thrust force, surface roughness, delamination factor, and cutting temperature were examined in the drilling of GFRP composites produced in unidirectional (UD), $\pm 45^{\circ}$ and $0^{\circ} / 90^{\circ}$ woven types. The effects of drilling parameters and the delamination factor on the tensile strength of the drilled specimen were also investigated. The result of this study indicated that thrust force, delamination factor, and surface roughness increased with increasing cutting speed and feed rate. An increase in feed rate decreased the cutting temperature while an increase in cutting speed increased the cutting temperature. Also, it was found that the delamination had a critical influence on the tensile strength of the GFRP composites.

\section{Introduction}

The application of composite materials has dramatically increased in the last decade owing to their mechanical properties such as high fracture strength, high corrosion resistance, high toughness, high strength-to-weight ratios, and high specific strength. Composites are used not only in structural applications, but also in electrical, thermal, tribological and environmental applications. Fiber-reinforced plastic (FRP) composites are the most commonly used composites. Due to their superior properties, FRP composites are increasingly used in various engineering applications such as automotive, aerospace, marine, nuclear industry, robot construction, and chemical industry [1-3]. For example, composite materials were used at $1 \mathrm{wt} . \%$ in the construction of Boeing-747 in 1969, 3 wt.\% in Boeing-757/767 in 1999, 11 wt.\% in Boeing-777 in 1993, and 50 wt.\% in Boeing-787 in 2013, respectively. Despite the increasing usage and superior mechanical performance, it is known that they have poor manufacturability properties. FRP composite materials are manufactured by using methods such as hand lay-up, spraying, molding under pressure, molding under vacuum, resin transfer method. Although these materials are produced close to the desired final form, composite parts often require a second process to achieve dimensional tolerance, surface quality, and other functional properties. Therefore, as a second process, machining methods such as drilling, turning, and milling are used to obtain the final shape.

The drilling process is used to open the holes required for the assembly of the FRP composite parts in construction. It is known that the 55000 holes in a single unit of Airbus A350, more than 100,000 holes in a small aircraft, and millions of holes in the manufacture of a large aircraft are required [4,5]. However, damages, which are not observed in the drilling of the metallic materials, occur in the drilling of FRP composites. These damages are fiber breakage, fiber/matrix breakdown, fiber breakdown, matrix 
cracking, tensile condensation, microcracks, deformation in the hole region, and hole surface quality [69].

After drilling of FRP composites, one of the observed basic damages is delamination. Delamination occurs at the entrance and exit areas of the hole due to cutting tool movements during drilling. Many composite parts cannot be used due to this delamination. For example, $60 \%$ of the composite parts are not accepted because of these damages in the aircraft industry [10]. The machining parameters and the cutting tool material and geometry must be appropriately selected to avoid these drawbacks. Incorrect selection of these parameters may cause unacceptable deformation. For this purpose, many studies have been carried out to protect the shape integrity of the FRP composite parts and to prevent them from being damaged.

Srinivasan et al. [11] investigated the influence of drilling parameters such as feed rate, cutting speed, and drill diameter on deformation in the drilling of GFRP composites. They indicated that the most effective parameter on deformation was feed rate. Davim et al. [12] performed a series of experiments on drilling of GFRP composite materials to understand the effects of drilling parameters on deformation and other material properties. They examined the effects of cutting parameters, tool geometry and material on deformation, thrust force, cutting pressure, and surface roughness. Kilickap [13] investigated the effects of cutting speed and feed rate on delamination using a drill bit with different point angles. It was reported that minimum delamination was obtained using a drill bit with narrow point angles in the drilling of GFRP composites. Besides, it was stated that the most important drilling parameter affecting delamination was the feed rate. Khashaba [10] conducted a study to investigate the effect of drilling parameters such as feed rate and cutting speed and material properties such as matrix, fiber type and orientation angle on thrust force, torque and deformation in the drilling of GFRP composites. In his study, he indicated that fiber woven type and drilling parameters significantly affected delamination. Also, it was stated that with increasing feed rate, the thrust force increased, and high thrust force significantly increased the delamination. Giasin and Ayvar-Soberanis [14] investigated the effects of cutting parameters on the drilled surface quality at the drilling of the GLARE composite. Besides, they investigated chip formation at the micro-level, and the diameter deviation and circularity, deformation at the entrance and the exit of holes, burr formation, fiber/matrix separation, fiber deterioration, and matrix cracks.

The occurred deformation in the drilling of the FRP composites significantly affects the mechanical properties of the parts and limits the life of the structures. The high deformation can reduce static strength, fatigue strength and compressive strength of the composite parts. Due to the load in the deformation region of the composite part, there is stress concentration. This situation causes quick deterioration of composite parts and leads to incapacitating of parts. Karimi et al. [15] investigated the effects of cutting speed and feed rate on deformation and compressive strength of deformed composite parts. They stated that the effect of feed rate on residual compressive strength was found to be greater than that of the cutting speed. It has been determined that the most effective cutting parameter on deformation and compressive strength was feed rate. Persson et al. [16] investigated the effect of deformation and damage in the drilling of carbon/epoxy composites on mechanical properties and 
fatigue life of the composites. They observed that damage significantly reduced the static and fatigue life of the parts. Montesano et al. [17] studied the tensile and fatigue strength of two different carbon fiber composites during conventional drilling and water jet drilling.

Studies in the literature investigated the effect of the drilling parameters and cutting tool characteristics on the delamination and the defect in the drilling of FRP composites. There are few studies on the effect of deformation on the strength of composites. Although there are comprehensive studies about the effects of drilling parameters and fiber woven types on the thrust force, delamination, surface quality, and cutting temperature, there are limited studies regarding the effect of delamination on tensile strength. The first aim of this work is to experimentally investigate the effects of fiber woven types and drilling parameters such as feed rate and cutting speed on the thrust force, cutting temperature, delamination factor, and cutting temperature. Secondly, it is to determine the effects of drilling parameters and the delamination factor on the tensile strength of GFRP composites.

\section{Materials And Methods}

\subsection{Materials}

Experiment samples to be used in the drilling of GFRP composites were produced as 16 layers by using vacuum infusion method. The vacuum infusion technique draws the epoxy that forms the composite matrix into the laminated structure inside the mold with vacuum pressure. With this method, better mechanical results are obtained compared to the hand lay-up method. E-glass fiber fabrics with different woven types were used as glass fiber. Density depending on area of glass fiber fabrics having UD (Unidirectional), $\pm 45^{\circ}$ and $0^{\circ} / 90^{\circ}$ woven types are 320,460 and $300 \mathrm{gr} / \mathrm{m}^{2}$, respectively. The diameter of the fibers forming the glass woven fabrics is 6-9 $\mu \mathrm{m}$. Three composite plates with three different woven types were produced and their thicknesses were $6 \pm 0.5 \mathrm{~mm}$. In the production of composites, it was used Epoxy LY 556 resin as matrix material and HY 917 as a hardener. The reinforcing element in the composites was $50 \mathrm{wt} . \%$ glass fiber. All the samples used in the experiments were cut in accordance with ASTM D 3039 standards $(6 \mathrm{~mm} \times 30 \mathrm{~mm} \times 200 \mathrm{~mm})$. The tensile strength of the test specimens prepared according to ASTM standard were determined by taking the average of three samples. The tensile strengths of undrilled GFRP composites having $0^{\circ} / 90^{\circ}$, UD and $\pm 45^{\circ}$ woven types are $330 \mathrm{MPa}, 252 \mathrm{MPa}$ and $42 \mathrm{MPa}$, respectively.

\subsection{Experimental Setup}

GFRP composites were drilled with different drilling parameters to determine the delamination factor, thrust forces, surface roughness, cutting temperature during drilling, and carried out the tensile test to determine the effect of delamination factor on the tensile strength of the drilled sample. Processes from the drilling of GFRP composites to the end of the tensile test are given in Figure 1 as a flow diagram. The workpiece was fixed on the dynamometer. During the experiment, cutting forces and temperatures were measured. The surface roughness of the hole surface was measured using the roughness device. The 
maximum diameter of the hole was determined using an optical microscope. Then, Tensile tests of the samples were done.

As seen in Figure 1, the test sample was fixed on the dynamometer. KISTLER 9257B type dynamometer, which has three components force measuring device, was used to record the thrust forces during the drilling of the GFRP composites. The received signals from the dynamometer were sent to the Kistler 5070A amplifier; then, these signals converted to thrust force using the Dynoware program. The cutting temperatures between the workpiece and the cutting tool were measured by the Testo 881-2 model infrared thermal camera. This instrument has a thermal sensitivity of $0.05^{\circ} \mathrm{C}$ and a temperature measuring range of -20 to $+350^{\circ} \mathrm{C}$. The roughness of the drilled surfaces of the workpiece was measured by using a Taylor Hobson's Surtronic $3+$ brand surface roughness device. Measurements were taken from 4 different points of the machined surface, and average surface roughness values (Ra) were calculated.

The drilling parameters are given in Table 1. Experiments were conducted out on the Brother Speedio S500X1 model vertical machining center using K 20 grade WC drill bit with $118^{\circ}$ tip angle. The power of the machine is $9.5 \mathrm{~kW}$, the maximum spindle speed is $10.000 \mathrm{rpm}$ and the number of turrets is 14 . According to the standards of SO230-2 2006, its sensitivity is $0.004 \mathrm{~mm}$.

Table 1. Drilling parameters

\begin{tabular}{|lll|}
\hline Parameters & Values & Symbol \\
\hline Cutting speed $(\mathrm{m} / \mathrm{min})$ & $25,50,75$ and 100 & $V$ \\
\hline Feed rate $(\mathrm{mm} / \mathrm{rev})$ & $0.05,0.10,0.15$ and 0.20 & $f$ \\
\hline
\end{tabular}

Deformations $\left(D_{\text {max }}\right)$ at the entrance and exit of the hole on the workpieces were measured using an optical microscope. An optical image of the drilled GFRP composite is given in Figure 2.

The delamination factors $\left(F_{d}\right)$ were determined using the formula in Equation 1 [18-19].

$$
F_{d}=D_{\max } / D_{\text {nom }}
$$

Where $D_{\max }$ is the maximum diameter in the deformation area, and $D_{\text {nom }}$ is the drill diameter.

Tensile tests were conducted at a constant speed of $1 \mathrm{~mm} / \mathrm{min}$ with a Shimadzu Autograph AG-X universal tester having a load cell of $250 \mathrm{kN}$ to determine the effect of the delamination factor on the tensile strength.

\section{Results And Discussions}


In industries where FRP composites are used as structure components, a vast number of holes are required for the assembly of FRP composites. Due to the structure of these materials, drilling parameters, geometry and material of cutting tool, and environmental factors, severe defects happen in the drilled zone and between layers. These defects in composites are seen as fiber-matrix interface separation, fiber breakage, and delamination. The presence of one or more of these defects in composite significantly reduces the strength and fatigue life of the material., The drilling parameters must be selected appropriately to keep these problems at a minimum level. The effects of feed rate and cutting speed on thrust force profile and maximum thrust force in the drilling of GFRP composites having different woven types are given in Fig. 3-4, respectively.

The thrust force mainly depends on cutting speed and feed rate. As seen from Figs. 3 and 4, when the spindle speed and feed rate were augmented, the the thrust force increased in the drilling of all woven types. When UD composites were drilled at $100 \mathrm{~m} / \mathrm{min}$ cutting speed and $0.05,0.1,0.15$ and $0.2 \mathrm{~mm} / \mathrm{rev}$ feed rate, thrust forces were obtained as $248,307,336$ and $388 \mathrm{~N}$ respectively. The thrust forces were measured as $123,185,223$ and $234 \mathrm{~N}$ respectively, in the drilling of $\pm 45^{\circ}$ composites at the same drilling parameters. Compared to UD composites, the thrust forces were found to be $57.7 \%, 62.3 \%, 61.9 \%$ and $59.8 \%$ less in the drilling of $\pm 45^{\circ}$ composites, respectively. When cutting speed is increased to $25,50,75$ and $100 \mathrm{~m} / \mathrm{min}$ at a constant feed rate of $0.1 \mathrm{~mm} / \mathrm{rev}$, thrust forces for UD composites are 200, 242, 291 and $307 \mathrm{~N}$, respectively, and thrust forces for $0^{\circ} / 90^{\circ}$ composites are 196, 215, 245 and $297 \mathrm{~N}$, respectively and thrust forces for $\pm 45^{\circ} 159$ composites are $120,150,159$ and $185 \mathrm{~N}$, respectively. The thrust forces obtained in the drilling of $\pm 45^{\circ}$ composites are $60 \%, 62 \%, 55 \%$ and $60 \%$ of the thrust forces obtained from the drilling of UD composites, respectively.

In the drilling of GFRP composites, the lowest and highest thrust forces are obtained from the woven type of $\pm 45^{\circ}$ and $0^{\circ} / 90^{\circ}$, respectively. The lowest thrust force was obtained as $96 \mathrm{~N}$ from the drilling of the composite having $\pm 45^{\circ}$ woven type at cutting speed of $25 \mathrm{~m} / \mathrm{min}$ and feed rate of $0.05 \mathrm{~mm} / \mathrm{rev}$. The highest thrust force was obtained as $391 \mathrm{~N}$ from the drilling of the composite having $0^{\circ} / 90^{\circ}$ woven type at cutting speed of $100 \mathrm{~m} / \mathrm{min}$ and feed rate of $0.2 \mathrm{~mm} / \mathrm{rev}$. It may be the reason for obtaining the lowest thrust force during the drilling of the composites having the $\pm 45^{\circ}$ woven type is that the fiber orientation is parallel to the plane of principal shear stress. For the $0^{\circ} / 90^{\circ}$ woven type, the fiber orientation is parallel to the principal plane stress. Therefore, the thrust force obtained is higher.

The change in the thrust force profile can be divided into four major regions according to the movement of the drill bit in the workpiece. These regions stage in the thrust force are given in Fig. 5 . The first zone is the time that passes up to beginning the drilling operation of the cutting edge of the tool, and thrust force increase quickly by starting from zero because the cutting tool in this region performs a scraping process instead of a cutting process.

The second region is where the cutting edge of the tool starts to a cutting process. The rate of increase in the thrust force in this region has a less slope when compared to the first region. In the third zone, the cutting edge performs completely cutting process, and the drill bit is into the workpiece. Thrust force is 
slightly higher than the second zone, and the slope of the curve is similar to the second zone. The fourth region is where the cutting tool tip starts to run out of the workpiece, and the drilling process is completed. The thrust force in this zone begins to decrease gradually, and the drilling process has been completed. As seen in Fig. 5, there are fluctuations in the thrust force indicated with a and $b$. These fluctuations have occurred from contact to fiber and epoxy of the drill bit. While the thrust force suddenly increased with the contact of the drill tip with the fiber, it has suddenly decreased with the contact of the drill tip with the epoxy.

The effects of the feed rate and cut speeds on the cutting temperature during the drilling of GFRP composites with UD, $\pm 45^{\circ}$ and $0^{\circ} / 90^{\circ}$ woven types have been experimentally investigated, and the results are shown in Fig. 6.

It was observed that the temperature observed between the cutting tool and the workpiece slightly decreased with increasing feed rate. It was thought that this decline caused by a decrease in contact time between the cutting tool and workpiece. On the other hand, the cutting temperature increased with increasing cutting speed because the friction between the cutting tool/workpiece increased. The maximum temperatures were obtained between $150^{\circ} \mathrm{C}$ and $250^{\circ} \mathrm{C}$ during the drilling of GFRP composites. Sorrentino et al. [20] found similar temperatures at the drilling of GFRP composites. The effect of drilling parameters on cutting temperature was obtained similarly for all woven types. The maximum temperatures obtained from the drilling of GFRP composites having UD, $\pm 45^{\circ}$ and $0^{\circ} / 90^{\circ}$ woven types at a cutting speed of $100 \mathrm{~m} / \mathrm{min}$ and a feed rate of $0.05 \mathrm{~mm} / \mathrm{rev}$ were $188^{\circ} \mathrm{C}, 200^{\circ} \mathrm{C}$ and $190^{\circ} \mathrm{C}$ respectively. The minimum temperature was obtained as $118^{\circ} \mathrm{C}$ by drilling of the GFRP composites having $\pm 45^{\circ}$ woven type at a cutting speed of $25 \mathrm{~m} / \mathrm{min}$ and a feed rate of $0.2 \mathrm{~mm} / \mathrm{rev}$.

The quality of the drilled surfaces plays an important role in the assembly line. Good surface quality considerably improves fatigue strength, corrosion resistance and friction life. One of the properties, which determine surface quality, is surface roughness. Surface roughness is significantly affected by drilling parameters. For this reason, appropriate machining parameters must be selected in order to minimize the surface roughness in the machining process. The effect of cutting speed and feed rate on surface roughness in the drilling of GFRP composites having different woven types is given in Fig. 7.

As seen in Fig. 7, higher surface roughness was obtained at high feed rates. This situation was the same for GFRP composites with all woven type. Low surface roughness was obtained from the feed rate of $0.05 \mathrm{~mm} / \mathrm{rev}$, while high surface roughness was obtained from the feed rate of $0.2 \mathrm{~mm} / \mathrm{rev}$. Furthermore, the surface roughness increased with increasing the cutting speeds. When $0 / 90$ composites were drilled at $25 \mathrm{~m} / \mathrm{min}$ cutting speed and $0.05,0.1,0.15$ and $0.2 \mathrm{~mm} / \mathrm{rev}$ feed rate, the surface roughnesses were obtained as $2.46,2.56,2.65$ and $2.71 \mu \mathrm{m}$ respectively. The surface roughnesses were measured as 4.02 , $4.24,4.35$ and $4.55 \mu \mathrm{m}$ respectively, in the drilling of $\pm 45^{\circ}$ composites at the same drilling parameters. Compared to $\pm 45^{\circ}$ composites, the surface roughness were found to be $61 \%, 60 \%, 61 \%$ and $60 \%$ less in the drilling of $0 / 90$ composites, respectively. Low surface roughness was obtained from the cutting speed of $25 \mathrm{~m} / \mathrm{min}$, and high surface roughness was obtained from the cutting speed of $100 \mathrm{~m} / \mathrm{min}$. The lowest 
surface roughness was obtained from the composites having the $0^{\circ} / 90^{\circ}$ woven type as $2.46 \mu \mathrm{m}$, while the highest surface roughness was obtained from of the composites having the $\pm 45^{\circ}$ woven type as $6.16 \mu \mathrm{m}$. The reason for the high surface roughness in high cutting speed is the fact that during cutting of the GFRP composite material, the cutting edge is faced with different fiber angles at every instant of the cutting process. The interaction angle between the cutting direction and the fiber orientation varies along the periphery of each layer of the composite, depending on the position of the cutting edge and fiber direction. This situation caused the bad surface quality because the cutting process carried out as the break, stretch and twist the fiber in the drilling of GFRP composites. Depending on the woven type, the lowest surface roughness was obtained from composites having the woven type of $0^{\circ} / 90^{\circ}$, while the highest surface roughness was obtained from composites having the woven type of $\pm 45^{\circ}$.

In the drilling of the GFRP composites, deformations occur in the entrance and exit of the hole. The maximum diameter of these deformations is measured, and the delamination factor is calculated using Eq. (1). The effect of drilling parameters such as cutting speed and feed rate on the delamination factor occurred; the entrance and exit of the hole are given in Fig. 8.

It can be seen that the delamination factor increased with increasing the feed rate and cutting speed. The lowest delamination factors were obtained $1.05,1.12$ and 1.1 respectively at the drilling of GFRP composites having UD, $\pm 45^{\circ}$ and $0^{\circ} / 90^{\circ}$ woven types at a cutting speed of $25 \mathrm{~m} / \mathrm{min}$ and a feed rate of $0.05 \mathrm{~mm} / \mathrm{rev}$. Maximum deformation occurred during drilling operations at $0.2 \mathrm{~mm} / \mathrm{rev}$ feed rate and $100 \mathrm{~m} / \mathrm{min}$ cutting speed. The deformation factor formed in the drilling GFRP composites having UD, \pm $45^{\circ}$ and $0^{\circ} / 90^{\circ}$ woven types in these drilling parameters is $1.6,1.89$ and 1.71 , respectively. At high feed rates, the cutting tool is found to not cut some of the fiber in the composite material. Due to the high thrust force generated by the increase in the feed rate, these uncut fiber are pushed in the direction of feed. This situation leads to severe deformations between the layers and especially in the last few layers of the composite. Krishnamorthy et al. [21] pointed out that because of the increase in the feed rate increased the contact between the workpiece and the cutting tool, the thrust force was high. Due to the low value of thermal conductivity of epoxy (about $0.363 \mathrm{~W} / \mathrm{mK}$ ), since the heat generated during the cutting process was not quickly thrown out, the heat generated accumulated around the drill bit, and this situates destroyed the stability of the matrix. The increase of temperature softens the matrix and reducing the bond strength between the fiber and the matrix; thereby, it leads to an increased deformation.

In the drilling of GFRP composites having three woven types, the effect of the delamination factor on the tensile strength of the sample are given in Figs. 9 and 10, respectively.

As seen in Fig. 9, the tensile strength value decreased with the increasing delamination factor. The maximum tensile strength of the GFRP composite having UD woven was obtained as $166 \mathrm{MPa}$ at 1.05 deformation factor value, while the minimum tensile strength was $120 \mathrm{MPa}$ at 1.6 deformation factor value. The minimum tensile strength is $72 \%$ of the maximum tensile strength. The maximum and minimum tensile strengths of the GFRP composite having $\pm 45^{\circ}$ woven type at 1.1 and 1.71 deformation values were determined as $38 \mathrm{MPa}$ and $27.5 \mathrm{MPa}$, respectively. In GFRP composites with $0^{\circ} / 90^{\circ}$ weaving 
type, the maximum tensile strength was determined as $249 \mathrm{MPa}$ at 1.12 deformation factor value and the minimum tensile strength was determined $211 \mathrm{MPa}$ at 1.89 deformation factor value. The drilling parameters and heat play an important role in the delamination factor in the drilling of GFRP composites. Due to the low value of the thermal conductivity of the matrix, the high temperature causes the matrix/fiber interface bond to weaken. Since the weakness of the interface bond causes the fibers to pull through the matrix, the tensile strength decreases. Tao et al. [22] reported that the formed delamination in the drilling of CFRP composites reduced the tensile strength of composite parts and that this reduction was approximately $15 \%$. This decrease in strength is mainly due to premature failure of the outer layers due to the incapability of the damaged interface to transfer stress from layers to layers.

The woven type of fiber has an important effect on the mechanical behaviour of the composites. As seen in Fig. 10, in the drilling of GFRP composites, the fiber woven types have revealed the size of delamination. As discussed previously, the feed rate is the most critical parameter that influences the delamination that occurs during drilling and, therefore, the tensile strength.

\section{Conclusions}

In this study, the effects of cutting speed, feed rate and woven type on thrust force, delamination factor, surface roughness, cutting temperature and tensile load were examined in the drilling of GFRP composites. As a result of the study, the following results were obtained.

- In high cutting speed and feed rates, the thrust force is high. The lowest and highest thrust force was obtained from the drilling of GFRP composites with $\pm 45^{\circ}$ and $0^{\circ} / 90^{\circ}$ woven types, respectively. The lowest thrust force was realized as $24 \%$ of the highest thrust force.

- Cutting temperature increased with increasing cutting speed and decreased with increasing feed rate. The lowest and highest cutting temperature were obtained from the drilling of GFRP composites with $\pm 45^{\circ}$ and UD woven type, respectively.

- With increasing cutting speed and feed rate, surface roughness increased. The lowest and highest surface roughness was obtained from the drilling of GFRP composites with $0^{\circ} / 90^{\circ}$ and $\pm 45^{\circ}$ woven type, respectively.

- The delamination factor of GFRP composites drilled at low cutting speed, and low feed rate was obtained lower. Consequently, tensile strengths were obtained higher.

- The tensile strength of the composites decreased with the high delamination factor. With the effect of the high thrust force and temperature, the matrix fiber interface bond is weakened and the tensile strength decreased. The woven types of the composite have a significant effect on the mechanical behavior of the composites.

\section{Declarations}

\section{Funding}


No funding was received to assist with the preparation of this manuscript.

\section{Conflicts of interest/Competing interests}

The authors have no relevant financial or non-financial interests to disclose.

\section{Code availability}

Not applicable

\section{Availability of data and material}

Not applicable

\section{Ethics approval}

Not applicable

\section{Consent to participate}

The authors agreed to participate in this research study.

\section{Consent for publication}

The authors agree to publish this research study.

\section{Authors' contributions}

E.K. and B.Y carried out the experiment. E.K. wrote the manuscript with support from Y.H.C. and B.Y. produced the samples.E.K. and Y.H.C. conceived the original idea.

\section{References}

[1] Miracle DB, Donaldson SL (2002) ASM Handbook Volume 21 Composites Material Park OH: USA, ASM international

[2] Palanikumar K, Davim JP (2007) Mathematical model to predict tool wear on the machining of glass fiber reinforced plastic composites. Mater Des. 28(7), 2008-2014

[3] Kilickap E, Yardimeden A, Celik YH (2015) Investigation of experimental study of end milling of CFRP composite. Sci Eng Compos Mater. 22(1), 89-98

[4] Arul S, Vijayaraghavan L, Malhotra SK, Krishnamurthy R (2006) The effect of vibratory drilling on hole quality in polymeric composites. Int J Mach Tools Manuf. 46(3), 252-259 
[5] Faraz A, Biermann D, Weinert K (2009) An innovative tool wear criterion in drilling CFRP composite laminates. Int J Mach Tools Manuf . 49(15), 1185-1196

[6] Abrao AM, Faria PE, Rubio JC, Reis P, Davim JP (2007) Drilling of fibre-reinforced plastics: A review. J Mater Process Technol.186(1), 1-7

[7] Bhattacharyya D, Horrigan DPW (1998) A Study of Hole Drilling in Kevlar Composites. Composites Science and Technology 58 (2), 267-283

[8] Kilickap E (2010) Investigation into the effect of drilling parameters on delamination in drilling GFRP. J Reinf Plast and Comp. 29(23), 3498-3503

[9] Azmi A, Lin RJT, Bhattacharyya D (2013) Machinability study of glass fibre-reinforced polymer composites during end milling. Int J Advan Manuf Techn.64 (1-4), 247-261

[10] Khashaba UA (2004) Delamination in drilling GFR-thermoset composites. Compos Struct. 63(3), 313327

[11] Srinivasan T, Palanikumar K, Rajagopal K, Latha B (2017) Optimization of delamination factor in drilling GFR-Polypropylene composites. Mater Manuf Process. 32(2), 226-233

[12] Davim JP, Reis P, António CC (2004) Experimental study of drilling glass fiber reinforced plastics (GFRP) manufactured by hand lay-up. Compos Sci Technol. 64(2), 289-297

[13] Kilickap E (2010) Analysis and modelling of delamination factor in drilling glass fiber reinforced plastic using Response Surface Methodology. J Compos Mater. 45(6), 727-736

[14] Giasin K., Ayvar-Soberanis S.: An Investigation of burrs, chip formation, hole size, circularity and delamination during drilling operation of GLARE using ANOVA. Compos Struct. 159(1), 745-760 (2017)

[15] Karimi NZ, Heidary H, Fotouhi M, Minak G (2017) Experimental analysis of GFRP laminates subjected to compression after drilling. Compos Struct. 169(1), 144-152

[16] Persson E, Eriksson I, Zackrisson L (1997) Effects of hole machining defects on strength and fatigue life of composite laminates. Compos Part A Appl Sci Manuf. 28(2), 141-151

[17] Montesano J, Bougherara H, Fawaz Z (2017) Influence of drilling and abrasive water jet induced damage on the performance of carbon fabric/epoxy plates with holes. Compos Struct. 163(1), 257-266

[18] Davim JP, Reis P, António CC (2004) Drilling fiber reinforced plastics (FRPs) manufactured by hand lay-up: influence of matrix (Viapal VUP 9731 and ATLAC 382-05). J Mater Process Technol, 155(1), 18281833

[19] Yardimeden A, Kilickap E, Celik YH (2014) Effects of cutting parameters and point angle on thrust force and delamination in drilling of CFRP. Mater Test. 56(11-12), 1042-1048 
[20] Sorrentino L, Turchetta S, Bellini C (2017) In process monitoring of cutting temperature during the drilling of FRP laminate. Compos Struct. 168, 549-561

[21] Krishnamoorthy A, Boopathy SR, Palanikumar K (2009) Delamination analysis in drilling of CFRP composites using response surface methodology. J Compos Mater. 43(24), 2885-2902

[22] Tao C, Qiu J, Yao W, Ji H (2016) The effect of drilling-induced delamination on tensile strength and prediction of residual strength of carbon fiber-reinforced polymer laminate. J Compos Mater. 50(24), 3373-3384 (2016)

\section{Figures}

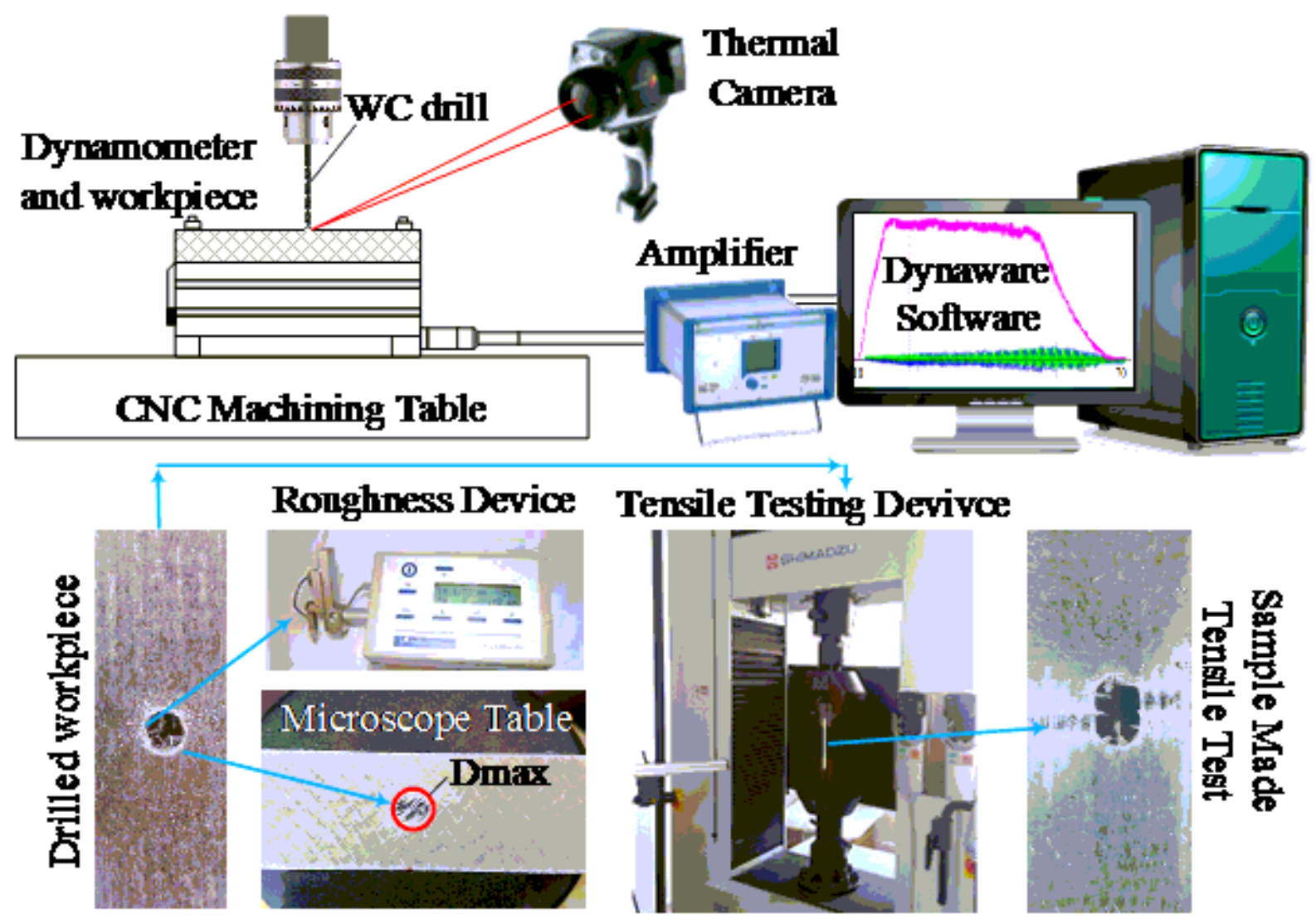

Figure 1

Flow chart for experimental setup of drilling of GFRP 


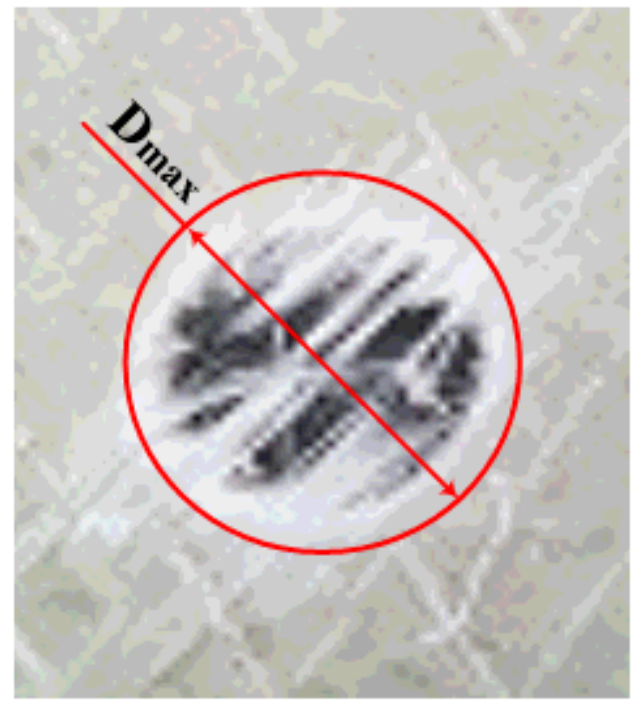

\section{Figure 2}

Dmax in the deformation area
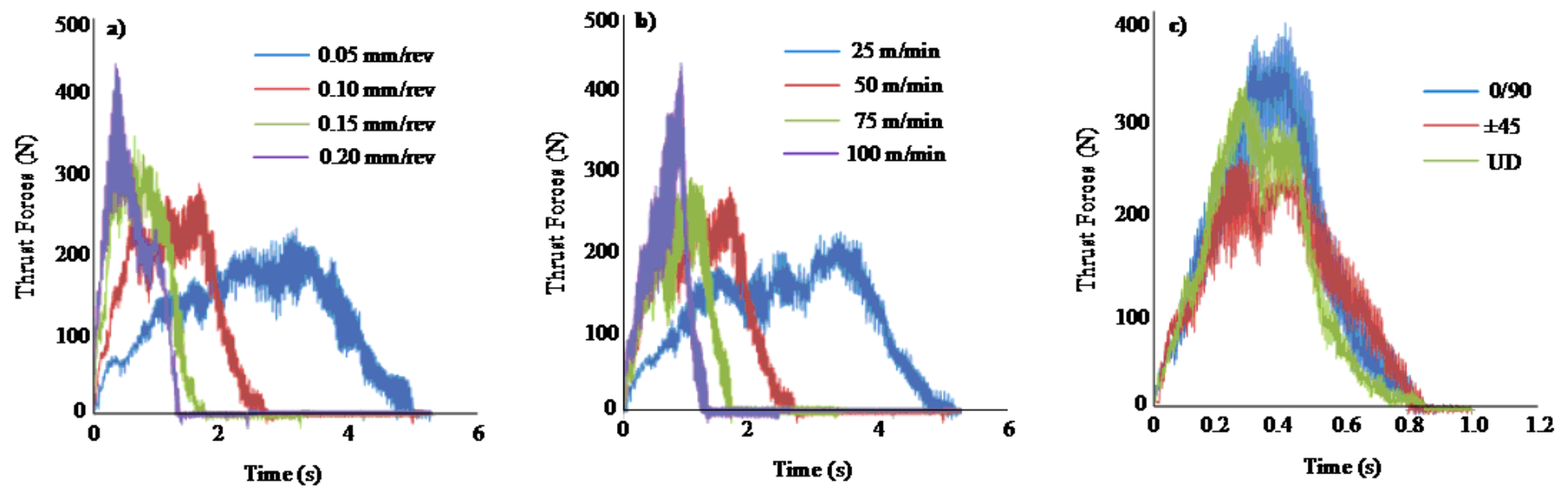

Figure 3

The effects of drilling parameters on thrust force profile drilling of GFRP composites having different woven type (WT), a) V: $25 \mathrm{~m} / \mathrm{min}, \mathrm{WT}: 0^{\circ} / 90^{\circ}$, b) f: $0.10 \mathrm{~mm} / \mathrm{rev}, \mathrm{WT}: 0^{\circ} / 90^{\circ} \mathrm{c}$ ) V: $100 \mathrm{~m} / \mathrm{min}$ f: 0.15 $\mathrm{mm} / \mathrm{rev}$ 

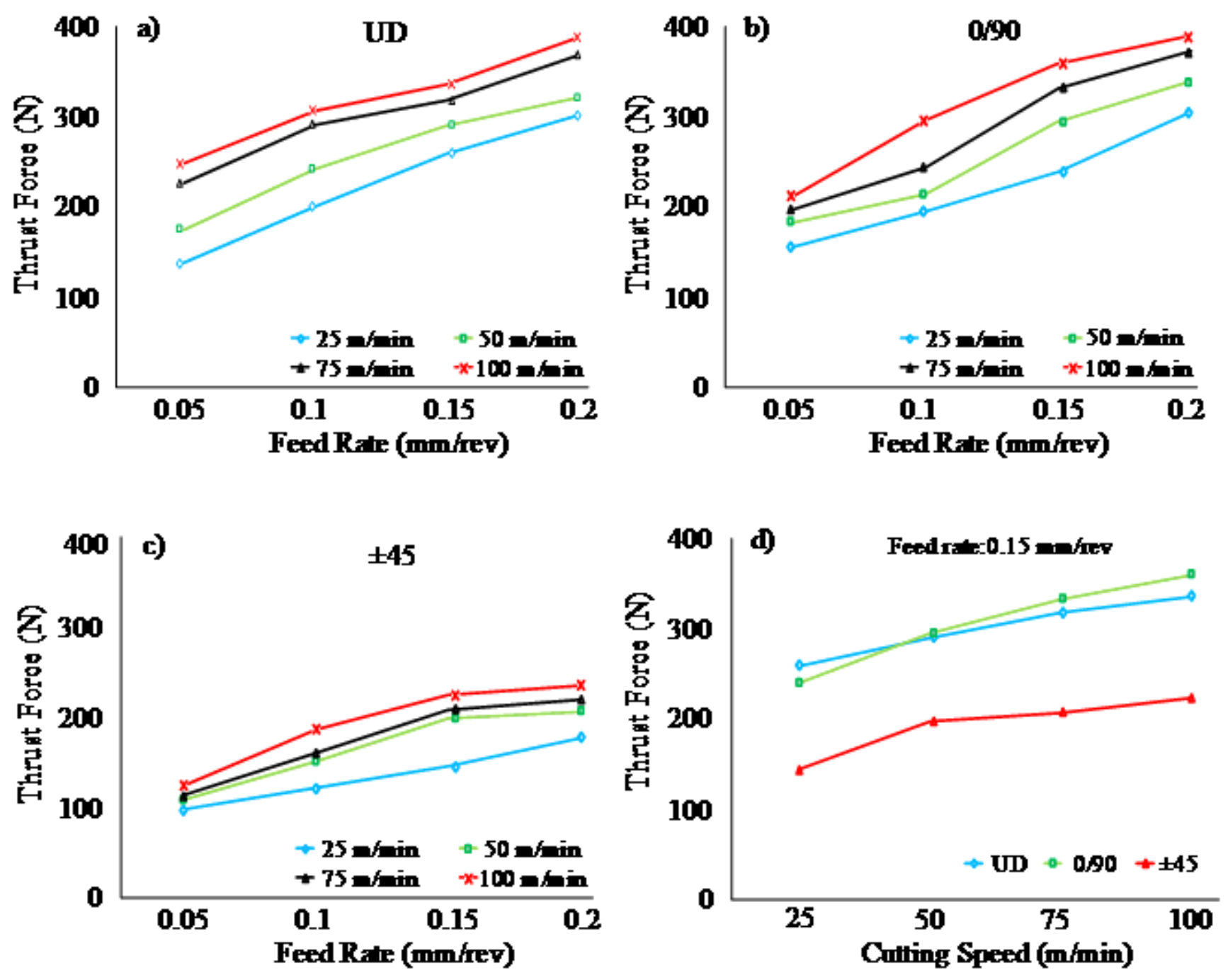

Figure 4

The effects of drilling parameters on thrust force

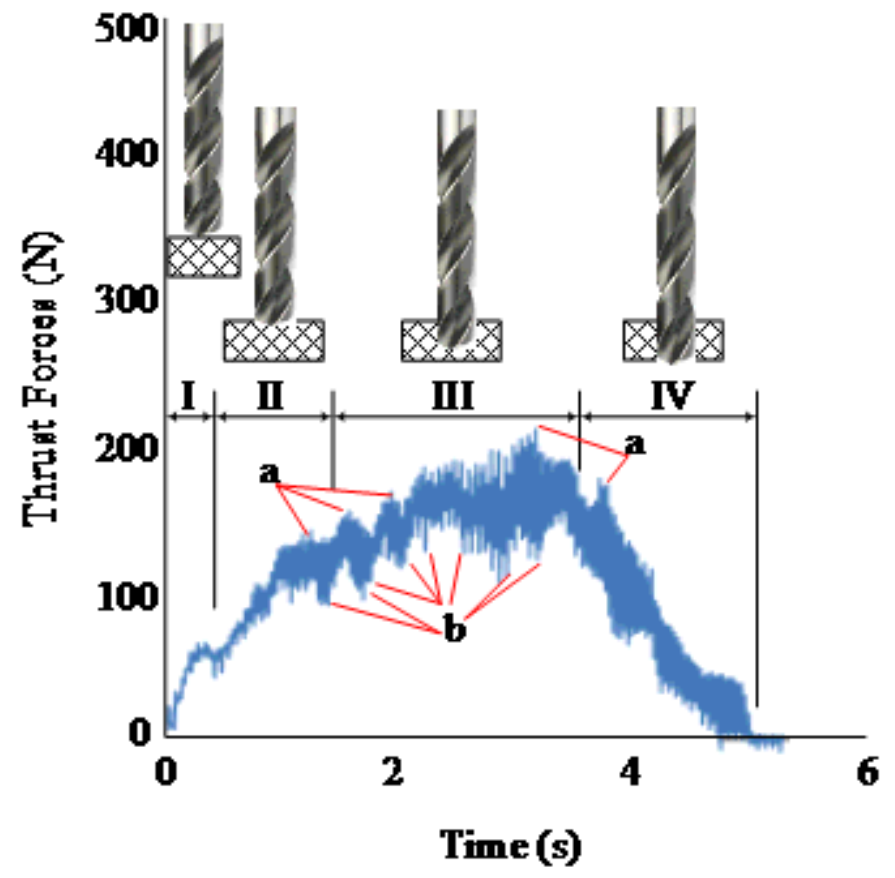


Figure 5

Thrust force depending on the time and the drill bit motion
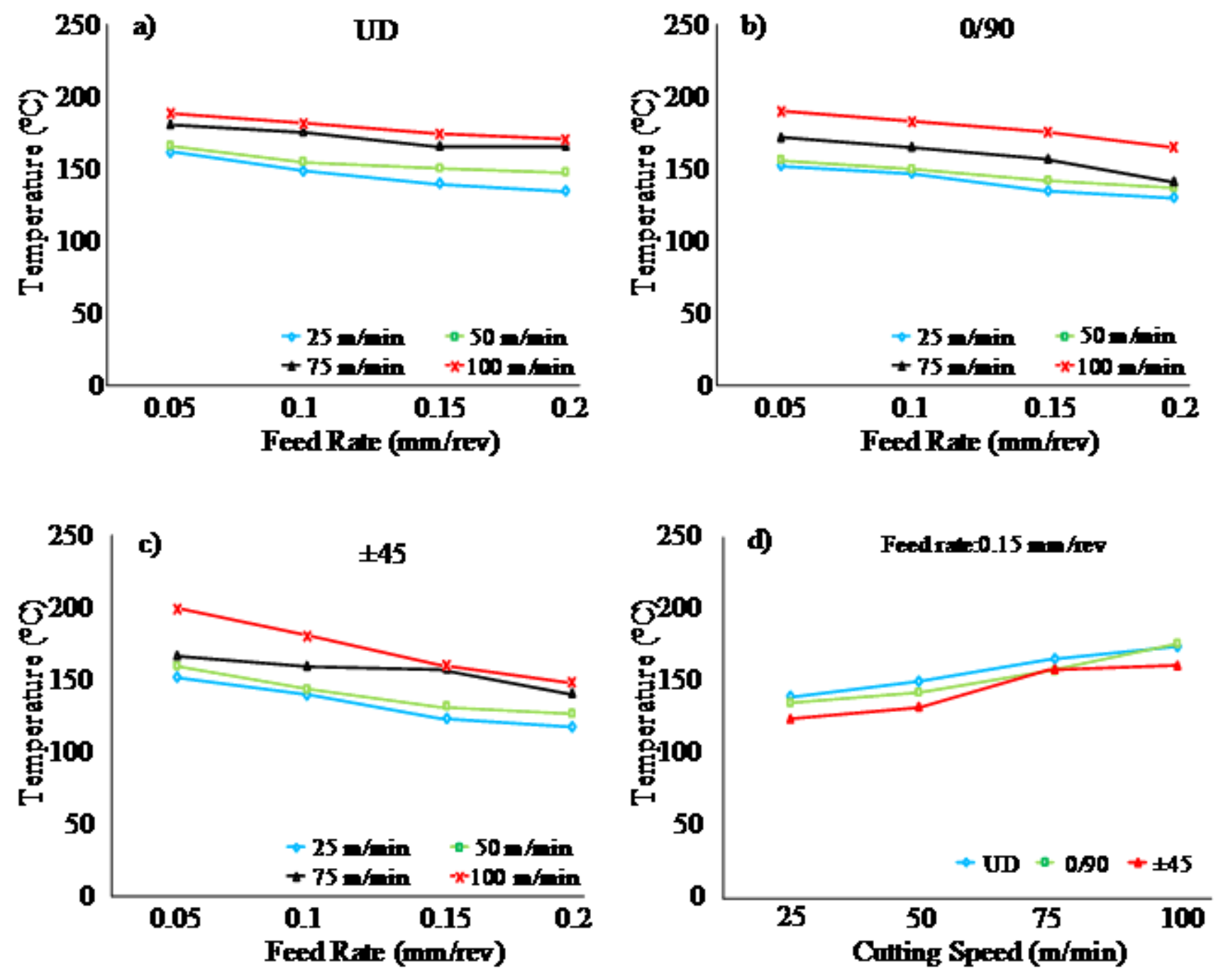

Figure 6

Effect of drilling parameters on cutting temperature 

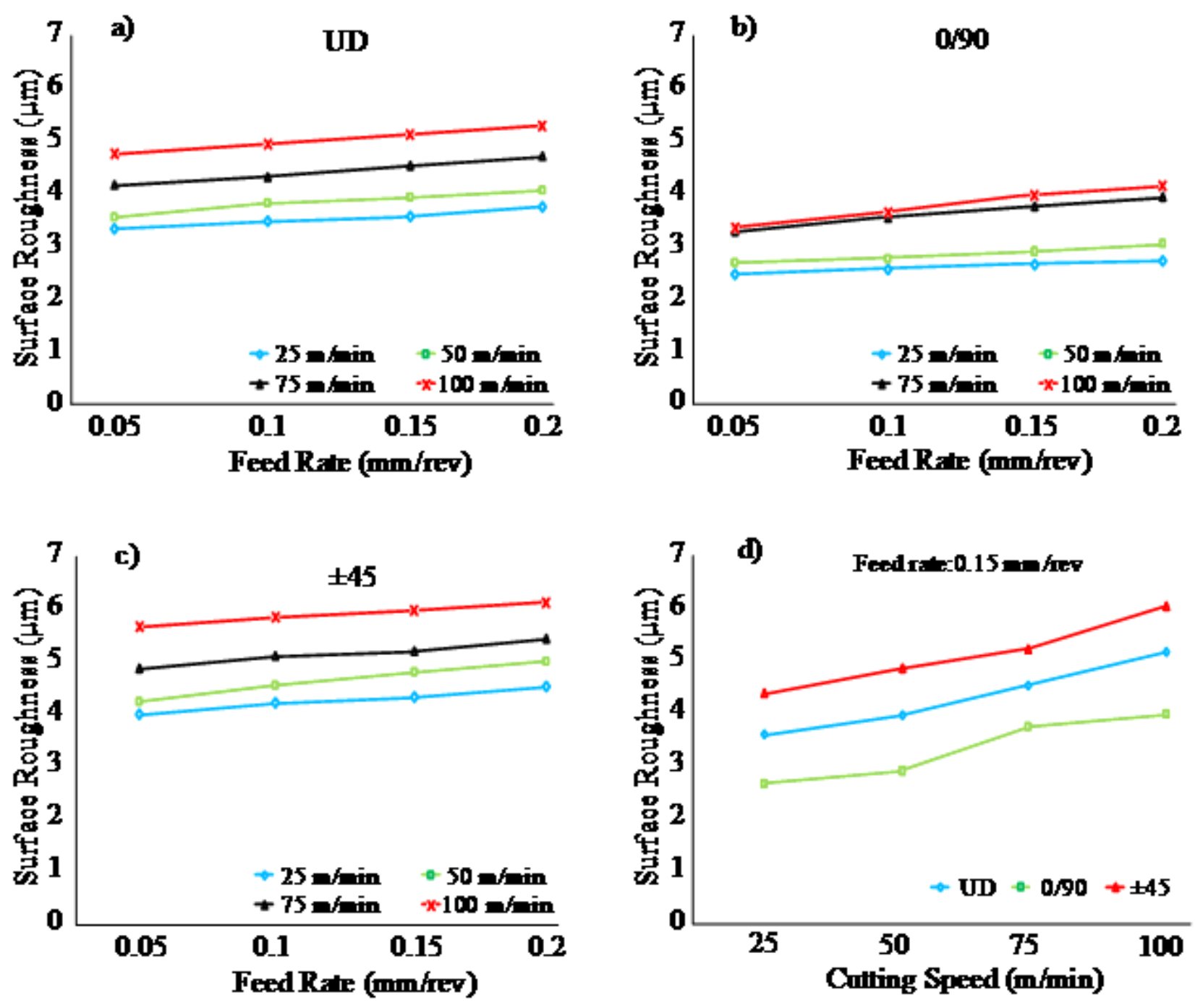

Figure 7

Effect of drilling parameters on surface roughness 

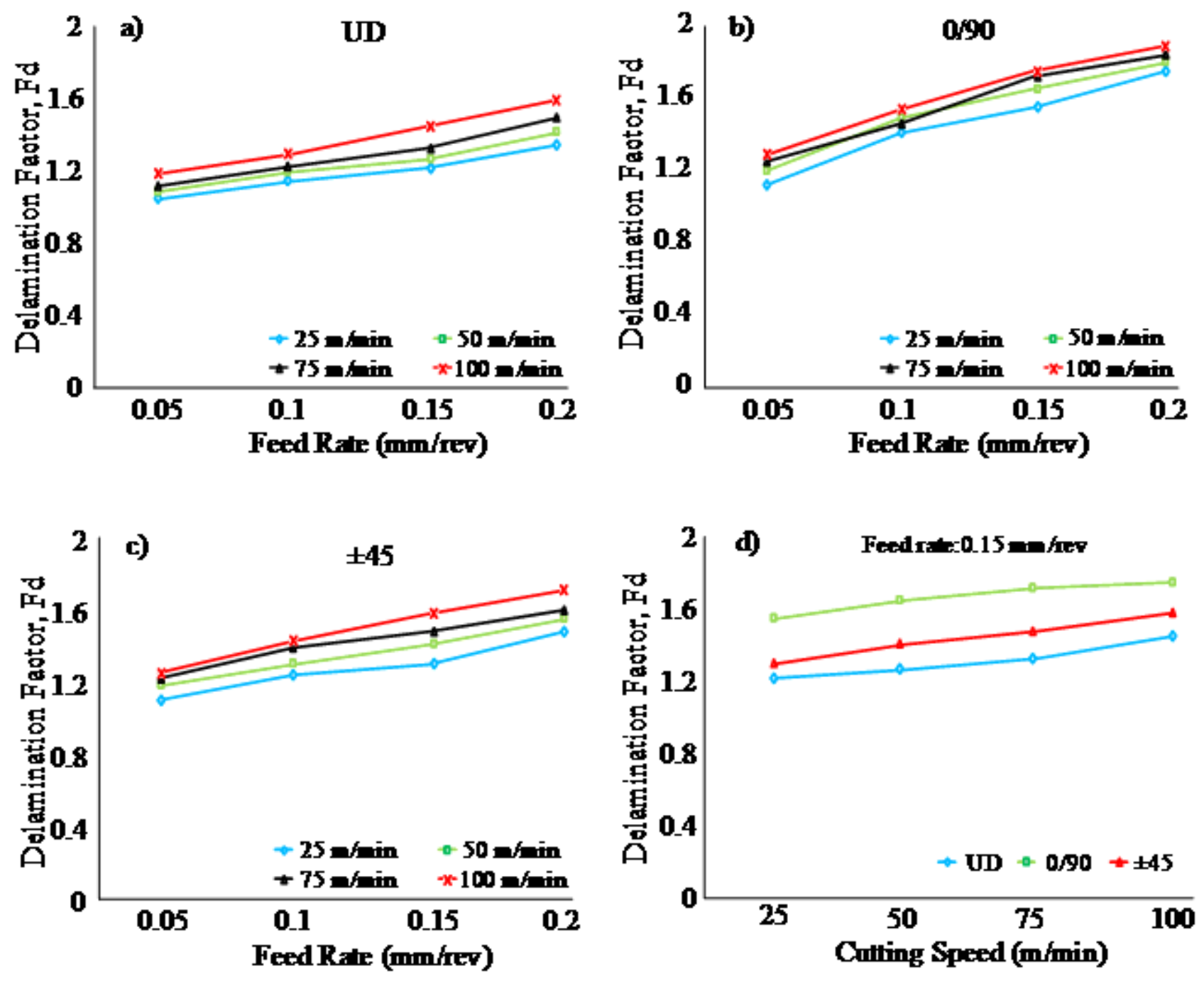

Figure 8

Effect of drilling parameters on delamination factor 


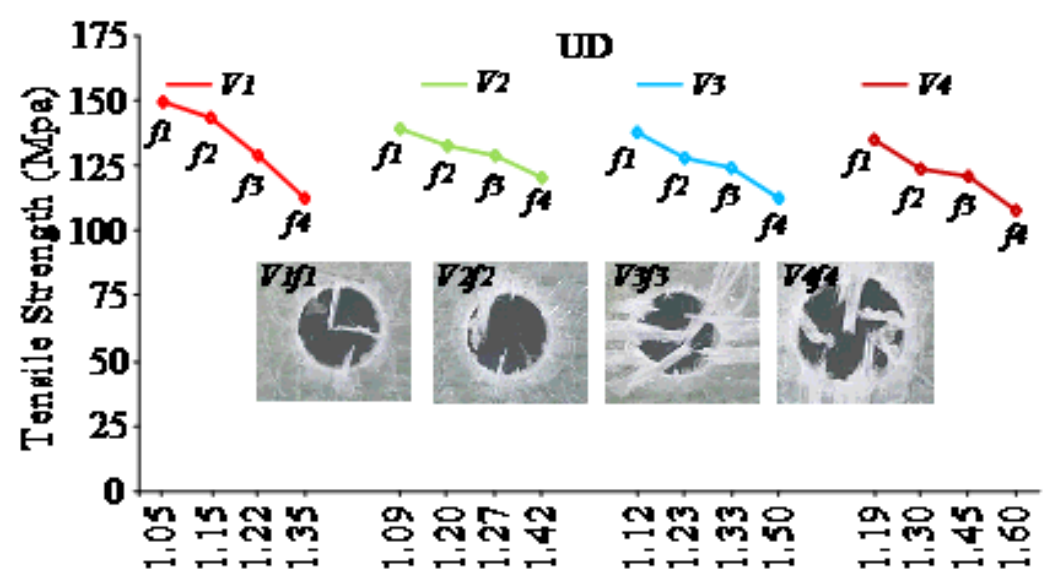

Delamination Fartor, Fd
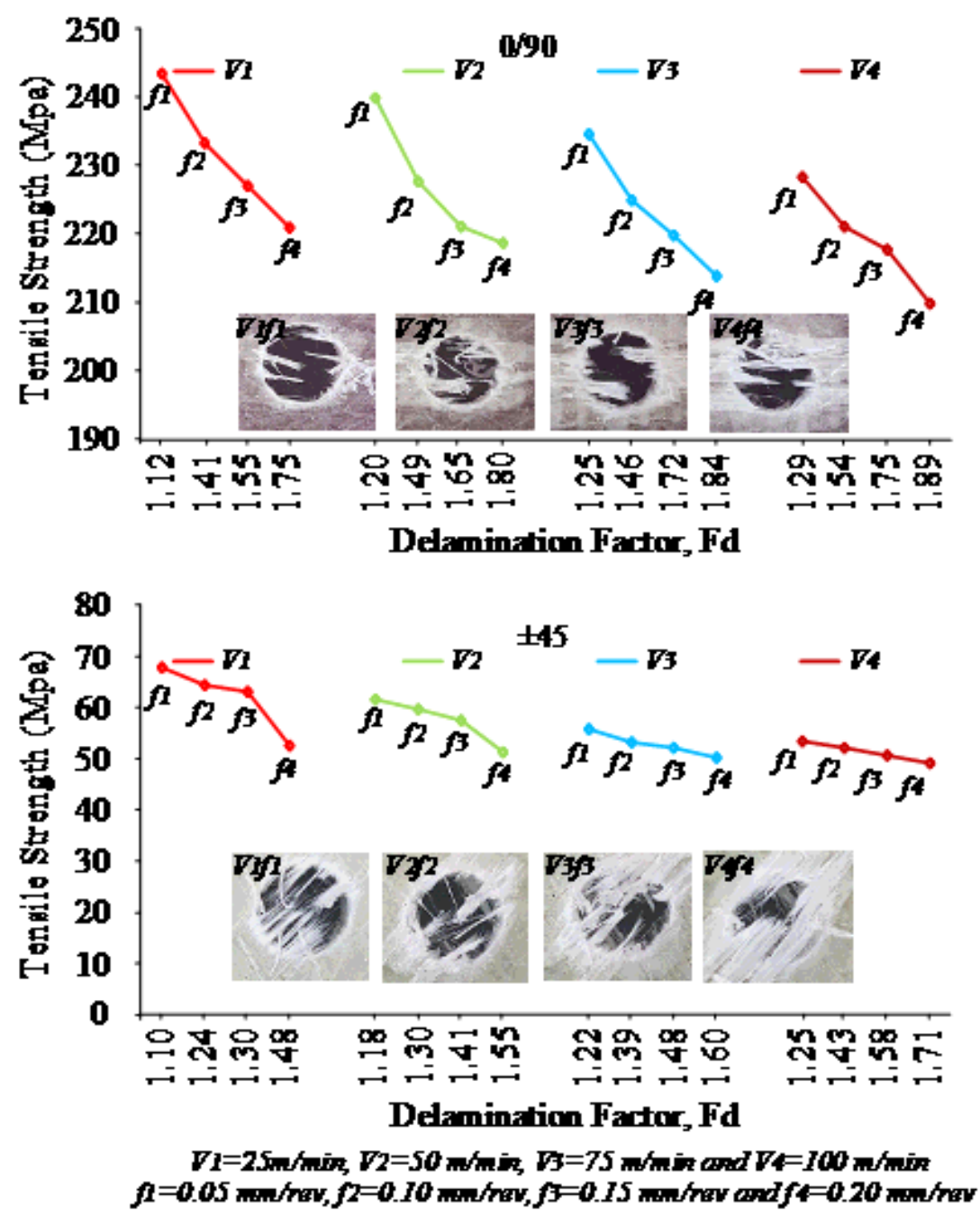

Figure 9

Effect of delamination factor on tensile strength 


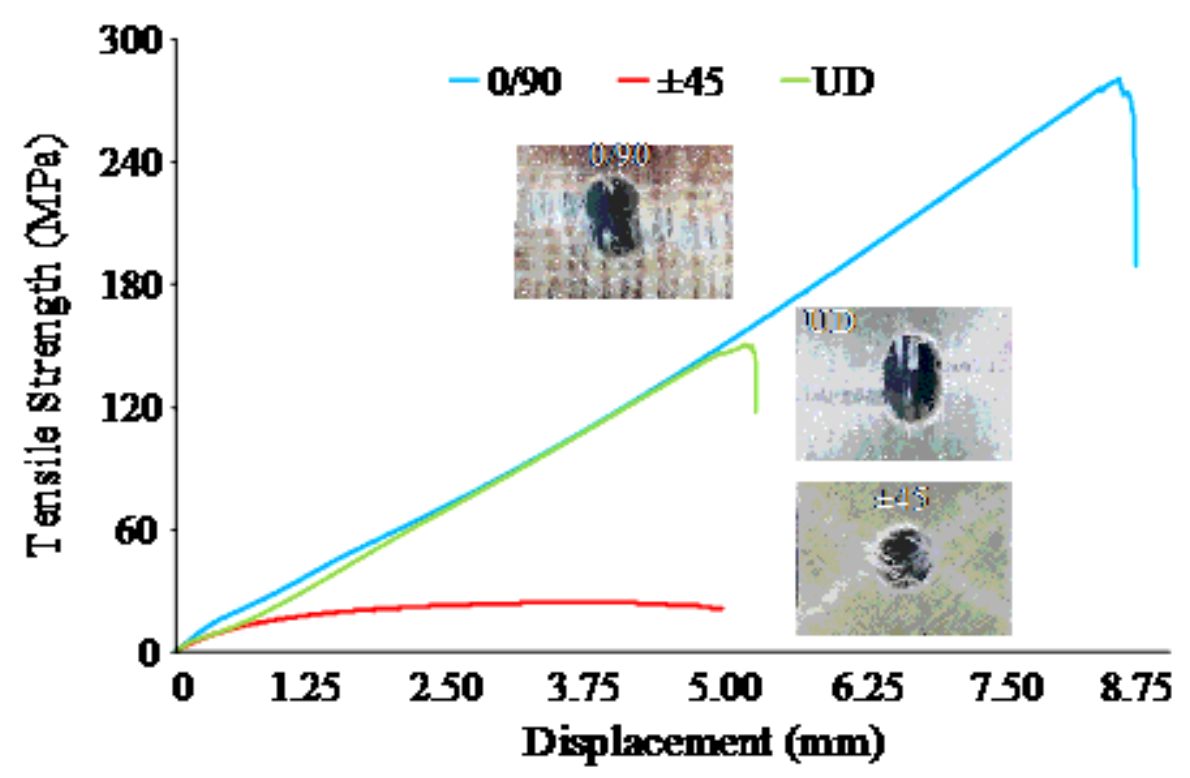

Figure 10

Tensile strength change depending composite types 